\title{
Migration and transformation of dissolved carbon during accumulated cyanobacteria decomposition in shallow eutrophic lakes: a simulated microcosm study
}

\author{
Zhichun Li ${ }^{1,2,3}$, Yanping Zhao ${ }^{4}$, Xiaoguang Xu ${ }^{\text {Corresp.. }}{ }^{4}$, Ruiming Han ${ }^{4}$, Mingyue Wang ${ }^{4}$, Guoxiang Wang ${ }^{\text {Corresp. }}$ \\ 1,4 \\ ${ }^{1}$ School of Geography Science, Nanjing Normal University, Nanjing, Jiangsu Province, China \\ 2 School of environmental science and mapping engineering, Suzhou University, Suzhou, Anhui Province, China \\ 3 National Engineering Research Center of Coal Mine Water Hazard Controlling, Suzhou, Anhui, China \\ 4 School of Environment, Nanjing Normal University, Nanjing, Jiangsu Province, China \\ Corresponding Authors: Xiaoguang Xu, Guoxiang Wang \\ Email address: xgxu@njnu.edu.cn, wangguoxiang@njnu.edu.cn
}

The decomposition processes of accumulated cyanobacteria can release large amounts of organic carbon and affect the carbon cycling in shallow eutrophic lakes. However, the migration and transformation mechanisms of dissolved carbon (DC) require further study and discussion. In this study, a 73-day laboratory microcosm experiment using suction samplers (Rhizon and syringe) was conducted to understand the migration and transformation of DC during the cyanobacteria decomposition. The decomposition of cyanobacteria biomass caused anoxic and reduction conditions, and changed the acidbase environment in the water column. During the early incubation (days 0-18), a large amount of cyanobacteria-derived particulate organic matter (POM) was decomposed into dissolved organic carbon (DOC) in the overlying water, reaching the highest peak value of $1.82 \mathrm{~g} / \mathrm{L}$ in the treatment added the high cyanobacteria biomass $(470 \mathrm{~g})$. After 18 days of incubation, the mineralization of increased DOC to dissolved inorganic carbon (DIC) maintained a high DIC level of overlying water in treatments added cyanobacteria biomass. The treatment added the medium cyanobacteria biomass $(235 \mathrm{~g})$ presented the lower DOC/TDC ratio than the high cyanobacteria biomass associated with the lower mineralization from DOC to DIC. Due to the concentration differences of DIC at watersediment interface, the main migration of DIC from pore water to overlying water occurred in the treatment without added cyanobacteria biomass. However, the treatments added the cyanobacteria biomass presented the obvious diffusion of DOC and the low migration of DIC at the water-sediment interface. The diffusive fluxes of DOC at the water-sediment interface increased with the cyanobacteria biomass added, reaching the maximum value of $411.01 \mathrm{mg} /\left(\mathrm{m}^{2} \cdot \mathrm{d}\right)$ in the treatment added the high cyanobacteria biomass. In the overlying water, the group added the sediment and medium cyanobacteria biomass 
presented a faster degradation of cyanobacteria-derived POM to DOC and a higher mineralization level of DOC to DIC than added the medium cyanobacteria biomass without sediment. Therefore, during accumulated cyanobacteria decomposition, the biomass of accumulated cyanobacteria and sediment property can influence the migration and transformation of DC, playing an important role in carbon cycling in shallow eutrophic lakes. 
1 Migration and transformation of dissolved carbon during accumulated cyanobacteria 2 decomposition in shallow eutrophic lakes: a simulated microcosm study

3 Zhichun $\mathrm{Li}^{\mathrm{a}}$, b, d, Yanping Zhao ${ }^{\mathrm{c}}$, Xiaoguang $\mathrm{Xu}^{\mathrm{c}}$, Ruiming Han ${ }^{\mathrm{c}}$, Mingyue Wang ${ }^{\mathrm{c}}$, Guoxiang

4 Wang ${ }^{\mathrm{b}, \mathrm{c}^{*}}$

5 a. School of Geography Science, Nanjing Normal University, Nanjing, China, 210023,

6 b. School of environmental science and mapping engineering, Suzhou University, Anhui, China,

$7 \quad 234000$

8 c. School of Environment, Nanjing Normal University, Nanjing, 210023, China

9 d. National Engineering Research Center of Coal Mine Water Hazard Controlling, Anhui, 234000,

10 China

11 *Corresponding authors. 1, Wenyuan Road, Xianlin University District, Nanjing 210023, China.

12 E-mail address: xxg05504118@163.com (X.Xu); wangguoxiang@njnu.edu.cn (G. Wang) 
23 Abstract: The decomposition processes of accumulated cyanobacteria can release large amounts

of organic carbon and affect the carbon cycling in shallow eutrophic lakes. However, the migration and transformation mechanisms of dissolved carbon (DC) require further study and discussion. In this study, a 73-day laboratory microcosm experiment using suction samplers (Rhizon and syringe) was conducted to understand the migration and transformation of DC during the cyanobacteria decomposition. The decomposition of cyanobacteria biomass caused anoxic and reduction conditions, and changed the acid-base environment in the water column. During the early incubation (days 0-18), a large amount of cyanobacteria-derived particulate organic matter (POM) was decomposed into dissolved organic carbon (DOC) in the overlying water, reaching the highest peak value of $1.82 \mathrm{~g} / \mathrm{L}$ in the treatment added the high cyanobacteria biomass $(470 \mathrm{~g})$. After 18 days of incubation, the mineralization of increased DOC to dissolved inorganic carbon (DIC) maintained a high DIC level of overlying water in treatments added cyanobacteria biomass. The treatment added the medium cyanobacteria biomass $(235 \mathrm{~g})$ presented the lower DOC/TDC ratio than the high cyanobacteria biomass associated with the lower mineralization from DOC to DIC.

Due to the concentration differences of DIC at water-sediment interface, the main migration of

DIC from pore water to overlying water occurred in the treatment without added cyanobacteria biomass. However, the treatments added the cyanobacteria biomass presented the obvious diffusion of DOC and the low migration of DIC at the water-sediment interface. The diffusive

41 fluxes of DOC at the water-sediment interface increased with the cyanobacteria biomass added, 
43 biomass. In the overlying water, the group added the sediment and medium cyanobacteria biomass

44 presented a faster degradation of cyanobacteria-derived POM to DOC and a higher mineralization

45 level of DOC to DIC than added the medium cyanobacteria biomass without sediment. Therefore,

46 during accumulated cyanobacteria decomposition, the biomass of accumulated cyanobacteria and

47 sediment property can influence the migration and transformation of DC, playing an important

48 role in carbon cycling in shallow eutrophic lakes.

\section{Introduction}

Carbon cycling in lakes, from a macro perspective, refers to the constant migration and transformation between gaseous carbon, dissolved carbon and solid or particulate carbon (Kuntz et al., 2015; Quay, 1986). DC can be found in the whole water column, is an important media for the transformation of other carbon forms and is conducive to absorption and utilization by aquatic plants and microorganisms (Bass et al., 2010; Koehler et al., 2016). DC, including DIC and DOC, originates from autochthonous production or allochthonous input. DIC $\left(\mathrm{CO}_{2}, \mathrm{CO}_{3}{ }^{2-}\right.$ and $\left.\mathrm{HCO}_{3}{ }^{-}\right)$is an important aquatic nutrient that influences the carbon cycle and is mainly produced in sediment pore water during organic matter oxidation. It is also influenced by soil $\mathrm{CO}_{2}$ from catchments, the influx or efflux of $\mathrm{CO}_{2}$ from or to the atmosphere, and the balance between photosynthetic $\mathrm{CO}_{2}$ uptake and respiratory $\mathrm{CO}_{2}$ production (Vreca, 2003; Mcdonald et al., 2013; Bass et al., 2010). DOC composition has been studied through the quantification of specific compounds, including short-chain organic acids, amino acids, and major classes of biomolecules (Komada et al., 2013;

Gómez-Consarn et al., 2012; Bertilsson, et al., 2003). In lake ecosystems, the autochthonous and 
63 allochthonous DOC refers to various autotrophic and heterotrophic in situ activities and the

64 hydrodynamic processes of catchments, respectively. Allochthonous DOC, typically deriving from

65 vegetation and soil organic matter, is more stable and resistant to degradation than autochthonous

66 DOC (Catalán et al., 2013; Tranvik, 1992; Jaffé et al., 2015). Autochthonous DOC is derived from

67 planktonic production, photosynthesis of macrophytes, and micro-biological degradation of

68 organic matter (Hu et al., 2011; Assunção et al., 2016). In eutrophic lakes, autochthonous DOC

69 mainly originates from phytoplankton biota detritus, particularly cyanobacteria blooms. The

70 transformation between DOC and DIC includes various biogeochemical processes, e.g.,

71 photochemical reactions, metal complexation, microbial growth, and nutrient and contaminant

72 transport, which affect the environmental behavior of pollutions and the carbon cycle of shallow

73 eutrophic lakes (Attermeyer et al., 2014; Aarnos et al., 2012; Marie et al., 2015; Yang et al., 2016).

74 Therefore, it is crucial to understand the migration and transformation of DC during cyanobacteria

75 decomposition in shallow eutrophic lakes.

76 Cyanobacterial blooms frequently occur in shallow eutrophic lakes. Depending on the

77 meteorological and hydrological conditions, a large amount of cyanobacteria biomass may drift

78 and accumulate along the lake shoreline (Kong and Gao, 2005; Yang et al., 2016), resulting in the

79 formation of an active carbon pool. Subsequently, these accumulated cyanobacteria are subjected

80 to sedimentation and decomposition processes, coupled with the migration and transformation of

81 DC. Compared with aquatic plants, cyanobacteria are relatively easily decomposed due to their

82 smaller grain size and more favorable ratio of nitrogen to phosphorus for microbial utilization (Li

83 et al., 2011; Sun, 2013; Wang et al., 2008; Liu et al., 2010). In addition, the growth period of 
cyanobacteria is generally shorter than that of aquatic plants, and their growth rates are faster. Therefore, the accumulation, sedimentation, and decomposition of cyanobacteria may accelerate contaminant transport, material cycling (carbon, nitrogen, and phosphorus) and energy flow in lake ecosystems. Studies have previously been conducted on cyanobacteria decomposition related to variability in total organic carbon (Hanamachi et al., 2008; Ye et al., 2011), bacterial community dynamics and biodegradability of cyanobacteria-derived OM (Lee et al., 2016; Shi et al., 2017), qualitative and quantitative variability in specific organic carbon compounds (Liu et al., 2016), and the accumulation and degradation of chromophoric dissolved organic matter (Hulatt et al., 2009). These studies revealed the contribution of cyanobacterial decomposition to the carbon cycle and associated influence factors, including microbial community characteristics, sunlight, temperature, and aerobic and anaerobic conditions. However, few studies have attempted to systemically explore the mechanisms of migration and transformation of DC and to calculate a balance between the aquatic phase and the sediment phase during cyanobacteria decomposition. This study seeks to describe DC release characteristics in overlying water, and the migration and transformation processes during cyanobacteria decomposition in shallow eutrophic lakes. Samples of cyanobacteria and sediment cores were collected from Taihu Lake for laboratory incubation. Variability in DC concentration from the overlying water, bottom water, and porewater was monitored depending on the thicknesses of the accumulated cyanobacteria layer (cyanobacteria biomass) and the absence or presence of sediments. DOC diffusive flux at the sediment-water interface was calculated by Fick's first law. It was hypothesized that the biomass of accumulated cyanobacteria and the physical, chemical, and biological structures of sediment 
105 significantly influence the DOC release intensity, the transformation between DOC and DIC, and

106 DC diffusion processes at the water-sediment interface in shallow eutrophic lakes. These

107 observations may be beneficial to understand the fates of accumulated cyanobacteria and the

108 carbon cycle of shallow eutrophic lakes.

109

110

111

112

113

114

115

116

117

118

119

120

121

122

123

124

\section{Materials and methods}

\subsection{Sample collection}

As the third largest freshwater lake in China, Taihu Lake is a typical shallow and eutrophic lake where cyanobacteria blooms frequently occur in summer. The summer monsoon drives cyanobacteria blooms to drift and accumulate to lakeshore, forming a high biomass of cyanobacteria scum in aquatic macrophyte-belts (Fig. 1). The accumulated cyanobacteria rarely spreads more widely across the sediment because of the obstruction by aquatic macrophyte-belts and their forming trenches. Subsequently, the massive decline and decomposition of cyanobacteria blooms in high temperatures probably cause negative impacts on the aquatic ecosystem, including the malodorous water, the death of fish and other aquatic organisms and even the occurrence of black bloom (Smith et al., 2008; Feng et al., 2014; Liu et al., 2017).

The sampling operation was executed near the Maodu River (N31²4'42.21", E12000'38.92") along the western shoreline of Taihu Lake in July, 2016 (Fig. 1), including open water and accumulated cyanobacteria area. The overlying water samples from two areas were collected after measuring physical and chemical parameters by calibrated probes from American Hach. The initial physical and chemical parameters as well as the initial concentrations of total 
125

126

127

128

129

130

131

132

133

134

135

136

137

nitrogen $(\mathrm{TN})$, total phosphorus (TP), ammonia nitrogen $\left(\mathrm{NH}_{4}{ }^{+}-\mathrm{N}\right)$, nitrate nitrogen $\left(\mathrm{NO}_{3}{ }^{-}-\mathrm{N}\right)$ and

DOC of the lake water in the two areas were showed in Table 1. The fresh cyanobacteria were sampled by using a $64-\mu \mathrm{m}$ plankton net. Three intact core sediments were collected using a $\mathrm{KC}$ Kajak core sampler equipped with a plexi-glass tube (inner diameter, $8.8 \mathrm{~cm}$ ). The overlying water and particulate matter were slowly sucked up using a small pump into the upper part of plexi-glass tubes that kept $25 \mathrm{~cm}$ of sediment below the sediment-water interface. The samples were stored in the refrigerator at $4^{\circ} \mathrm{C}$ and taken to the laboratory within 8 hours.

\subsection{Microcosm system}

Before the incubation of intact core sediments in the laboratory, the same volume $\left(40 \mathrm{~cm} \times \pi \times 4.4^{2} \mathrm{~cm}^{2}\right)$ of lake water from open water was slowly added into each plexi-glass tube (inside radius, $4.4 \mathrm{~cm}$ ) with minimal disturbance (Fig. 2). A plexi-glass tube without sediment and Rhizon samplers (Seeberg-Elverfeldt et al., 2005; Shotbolt, 2010) served as the control. After one week of incubation, $0 \mathrm{~g}(0 \mathrm{~cm}), 235 \mathrm{~g}(5 \mathrm{~cm})$, and $470 \mathrm{~g}(10 \mathrm{~cm})$ of wet cyanobacteria biomass that had been washed with high purity water were added into three water columns labeled S, SM, and $\mathrm{SH}$, respectively. Meanwhile $235 \mathrm{~g}(5 \mathrm{~cm})$ of cyanobacteria biomass was added to the control system, labeled M. Cyanobacteria biomass was added based on field observations along the lakeshore where cyanobacteria had accumulated at a thickness of 5-10 cm. The incubation experiment was performed in an air-conditioned lab and was always kept at $28^{\circ} \mathrm{C}$ using an automatic constant temperature heating rod. To better represent in-situ conditions in Taihu Lake, the upper parts of the plexi-glass tubes were opened and their entire sides protected from light. To 
145 collect pore water, three plexi-glass tubes with $25 \mathrm{~cm}$ intact core sediments were fitted to the

146 Rhizon samplers at $0 \mathrm{~cm}, 2 \mathrm{~cm}$, and $4 \mathrm{~cm}$ depths below the sediment-water interface (Seeberg-

147 Elverfeldt et al., 2005; Shotbolt, 2010).

148

149

150

151

152

153

154

\subsection{Sample analysis}

The thicknesses of cyanobacterial layer on surface water and sedimentary detritus layer (cyanobacteria-derived particulates) on surface sediment were measured by straightedge. Dissolved oxygen (DO), $\mathrm{pH}$, and oxidation-reduction potential (Eh) of overlying water were detected using calibrated probes from American Hach. Syringes were used to extract $5 \mathrm{~mL}$ of overlying water, $5 \mathrm{~mL}$ of bottom water, and $2.5 \mathrm{~mL}$ of pore water for the respective groups $\mathrm{S}, \mathrm{SM}$, and $\mathrm{SH}$, while $5 \mathrm{~mL}$ of overlying water for group $\mathrm{M}$ was collected. Subsequently, the same volume of lake water with extracted water was supplemented into each column. The overlying water samples were filtered through precombusted $\left(470^{\circ} \mathrm{C}\right.$ for $\left.4 \mathrm{~h}\right) \mathrm{GF} / \mathrm{F}$ glass fiber filters (nominal pore size, $0.7 \mu \mathrm{m}$; Whatman International Ltd., Maidstone, England). DIC and total dissolved carbon (TDC) values from filtered overlying water and pore water were directly detected using carbonnitrogen analyzer (multi N/C® 3100, AnalytikJena, Germany). The carbon-nitrogen analyzer applied the method of combustion oxidation-non-dispersive infrared absorption and the calculation model of minusing, which meant first determining TDC and DIC concentrations and then calculating the DOC concentrations (DOC $=$ TDC-DIC).

\subsection{Diffusive flux of DOC at the sediment-water interface}


165 law of diffusion:

166

168

169

170

171

172

173

174

175

176

177

178

179

180

181

182

183

$$
J=-\phi D_{s} \frac{\partial C}{\partial X}
$$

Where, $\phi$ is the porosity of surficial sediments. According to Cermelj (1997), the $\phi$ value in this study was set to 0.68 based on the weight fraction of water after drying the sediments for $24 \mathrm{~h}$ at $105^{\circ} \mathrm{C} . D_{S}$ is the bulk sediment diffusion coefficient for DOC, and the Stokes-Einstein equation yielded a value of $1.22 \times 10^{-6} \mathrm{~cm}^{-2} \mathrm{~s}^{-1}$ according to the average molecular weight for DOC of 8000 daltons (Alperin et al., 1994; Holcombe et al., 2001). Therefore, based on the literature on the average molecular weight of pore water DOC (Burdige et al., 1999), the $D_{S}$ was assumed to be $1.22 \times 10^{-6} \mathrm{~cm}^{-2} \mathrm{~s}^{-1}$ to assess the DOC diffusive flux in this study. $\partial C / \partial x$ is the DOC concentration gradient between pore-water and bottom water over the applied distance, where $\partial C / \partial x$ can be approximated by $\Delta C / \Delta x$ (Burdige et al., 1999; Lahajnar et al., 2005). $\Delta C$ is the difference in DOC concentration between bottom water and pore water sampled at $2 \mathrm{~cm}$ depth. $\Delta x$ is the vertical dimension between two sample points (i.e. $\Delta x=2 \mathrm{~cm}$ in the microcosm system).

\subsection{Statistical analysis}

Temporal variability and box-plots for TDC, DOC, and DIC concentrations and DOC diffusive flux were analyzed using Origin version 8.0 and SPSS statistical package 19.0 (SPSS Inc., Chicago). The correlation analysis between the physicochemical indexes and DC concentrations was conducted using the SPSS statistical package for Windows. The criteria of $p<$ 0.05 was considered as the significant level in this study. 
184

185

186

187

\section{Results and Discussion}

\subsection{Visual changes and physicochemical environment associated with DC release}

During cyanobacteria decomposition, the thickness of the cyanobacteria layer on superficial overlying water and the thickness of sedimentary detritus layer from cyanobacteria-derived particulates at the bottom of overlying water are shown in Fig. 3. In the treatment without cyanobacteria biomass (group S), the water column remained relatively colorless and transparent during the experiment. However, the overlying water in groups with added cyanobacteria biomass (groups SM, SH and M) gradually showed variations in visible color and thickness with a foul smell. From day 2 to day 10 there was a slight odor and a large amount of cyanobacteria-derived particulates dispersed into the water column for groups SM, SH and M. Due to the abundant chlorophyll-a in fresh cyanobacteria (Shoaf and Lium, 1976; Zarel et al., 2015), the overlying water displayed the green color, indicating cyanobacteria hadn't been completely decomposed during early incubation. After 10 days, the water color became yellow-green with a strong odor when the cyanobacteria layers in overlying water became incompact and a low aggregation degree. This indicated the massive decomposition of the cyanobacteria-derived POM. Subsequently, a number of black particles appeared in the overlying water and sediments, which was similar to previous reports (Steinberg, 2003; Duan et al., 2014; Han et al., 2015) and probably related to the settling of POM. After the 20th day, the sedimentary detritus layer at the bottom decreased in thickness and black particles gradually disappeared. These changes might have occurred with the microbial mineralization of cyanobacteria-derived POM (Shi et al., 2017). Therefore, in the 
204

205

206

207

208

209

210

211

212

213

214

215

216

217

218

219

220

221

222

223

224

treatments added cyanobacteria biomass, the clear color changes in the water column and the morphological changes in the cyanobacteria layer can indicate the degradation level of cyanobacteria-derived POM to some extent.

Variations in $\mathrm{DO}$, Eh and $\mathrm{pH}$ values in the water column according to incubation time are shown in Fig. 4. Based on the initial DO and Eh values, there was no obvious reduction environment in the overlying water, similar to the data of open water in Taihu Lake (Table 1). After adding cyanobacteria, DO concentrations of the water column in groups $\mathrm{SM}, \mathrm{SH}$, and $\mathrm{M}$ began to rapidly decrease and remained at a lower level $(<1.0 \mathrm{mg} / \mathrm{L})$, compared to group $\mathrm{S}$ without cyanobacteria biomass. The change trends between DO and Eh were basically consistent, corresponding to the data of accumulated cyanobacteria in Taihu Lake (Table 1). Meanwhile, DOC and DO in groups M, SM and SH with added cyanobacteria biomass were negatively correlated (r $=-0.328 \sim-0.310, p<0.05)$ (Table 2). This indicated that the DOC release from microbial degradation of organic matter probably consumed oxygen and resulted in anoxic conditions, consistent with previous studies (Shao et al., 2013; Song et al., 2016; Yan et al., 2017). The water column was alkaline at the beginning of the experiment. After adding cyanobacteria, the $\mathrm{pH}$ values of the water column in groups SM, SH and M had clear acid-base changes (Fig. 4c). During the first 18 days, the $\mathrm{pH}$ values in groups $\mathrm{SM}, \mathrm{SH}$ and $\mathrm{M}$ were lower and fluctuated. Subsequently, they gradually rose to peak values $(>8.5)$ and then dropped after that. In contrast, $\mathrm{pH}$ values in group $\mathrm{S}$ without biomass fluctuated more than 7.0. DOC and $\mathrm{pH}$ in groups $\mathrm{SM}, \mathrm{SH}$ and $\mathrm{M}$ were negatively correlated $(\mathrm{r}=-0.533 \sim-0.202, p<0.05)$, as shown in Table 2 . It is well documented that the decomposition of cyanobacteria causes biological, physical, and chemical degradation of 
225 proteins, lipids, and carbohydrates (Brown et al., 1997; Tibbetts et al., 2015). The degradation

226 process can produce many secondary metabolites and final products, which probably change the

227 acid-base environment, e.g., organic acids (Steinberg, 2003). Meanwhile, the strong positive

correlation between DIC and $\mathrm{pH}(\mathrm{r}=0.581 \sim 0.817, p<0.05)$ as well as high $\mathrm{pH}$ values $(>8.0)$

after 26 days of incubation indicated that the growth of microbes utilized DOC to generate $\mathrm{CO}_{2}$

(DIC) in groups SM, SH and M (Shao et al., 2013; Yan et al., 2017), causing the water column to

become alkaline. In summary, cyanobacteria decomposition can affect redox (anaerobic dominated) and the acid-base environment in the water column.

\subsection{Influence of cyanobacteria biomass on the release of DC in overlying water}

are shown in Fig. 5. Obviously, the more cyanobacteria biomass was added, the higher TDC and

DOC concentrations were detected. The box-plots also showed that TDC and DOC values in group

$\mathrm{SH}$ added the high cyanobacteria biomass were much higher than in group $\mathrm{S}$ without added cyanobacteria biomass and in group SM added the medium cyanobacteria biomass (Fig. 6a and 6b). During cyanobacteria decomposition, various organic carbon compounds found in cyanobacteria are released into the water column as DOC and POC, while different carbon fractions and other elements migrate and transform (Brocke et al., 2015; Chen et al., 2016). In this study, different concentrations of cyanobacteria biomass released different organic carbon compound content into the overlying water under the same physicochemical and biological conditions. In the initial 16 days, the cyanobacteria layer was greater than $0 \mathrm{~cm}$ in thickness (Fig. 
245

246

247

248

249

250

251

252

253

254

255

256

257

258

259

260

261

262

263

264

265

3), DOC and DTC concentrations gradually increased (Fig. 5a and 5b), and there was little changes in DIC concentrations in groups SM and SH (Fig. 5e). This indicated that the release rate of DOC was higher than the conversion rate in overlying water. The more cyanobacterial biomass was added, the higher the peak value of DOC concentrations $(\mathrm{S}, 153.9 \mathrm{mg} / \mathrm{L} ; \mathrm{SM}, 835.1 \mathrm{mg} / \mathrm{L}$ and SH, $1823.7 \mathrm{mg} / \mathrm{L})$. After 16 days, compared with small changes in DIC and DOC concentrations in group S, the obvious decrease in TDC and DOC content and the DOC/TDC ratio, along with the rapid rise in DIC concentrations in groups $\mathrm{SM}$ and $\mathrm{SH}$ demonstrated that DOC transformed into DIC in overlying water. This was similar to the aquatic macrophytes decomposition (Sobek et al., 2006; Assunção, 2016), probably involving the microbial mineralization of dissolved humic substances (Steinberg, 2003; Marie et al., 2015). In addition, the treatment added the medium cyanobacteria biomass (group SM) presented the lower DOC/TDC ratio than the high cyanobacteria biomass (group $\mathrm{SH}$ ) associated with the lower mineralization from DOC to DIC. This is probably because the decomposition of high cyanobacteria biomass consumed more oxygen and disturbed a recovering redox state. Cyanobacteria biomass variously affected the release of organic carbon and oxidative transformation from DOC to DIC.

In the microcosm with more biomass added, the $\mathrm{pH}$ values in overlying water were lower (Fig. 4c), probably due to more organic acids being produced by more cyanobacteria biomass during the decomposition processes. Generally, the more cyanobacteria biomass added, the higher DIC content detected (Fig. 4e). This trend indicated that the decomposition of more cyanobacteria biomass can release more carbon substrates and nutrients supporting microorganism growth in the water column, corresponding to the differences of $\mathrm{TN}, \mathrm{TP}, \mathrm{NH}_{4}{ }^{+}-\mathrm{N}, \mathrm{NO}_{3}^{-}-\mathrm{N}$ and DOC between 
266

267

268

269

270

271

272

273

274

275

276

277

278

279

280

281

282

283

284

285

open water and accumulated cyanobacteria area of Taihu Lake (Table 1). The growth of microbes can promote the microbial mineralization of more DOC and cyanobacteria-derived POM into DIC (Shao et al., 2013; Yan et al., 2017). According to the carbon budget calculation approach in previous studies (Sobek et al., 2006; Cremona et al., 2014), the differences (D-values) between the max TDC concentration during the incubation time and the sum of DOC and DIC values in the final stage can clarify the amount of migration and transformation of TDC into sediment or air, partly based on the presence of odorous substances (Smith et al., 2008; Yu et al., 2016; Liu et al., 2017). D-values comparison between incubation groups is shown in Fig. 6d. Treatments with more cyanobacteria biomass had higher D-values. This confirmed that the amount of migration or transformation of DC was related to the amount of added cyanobacteria biomass. In summary, the added cyanobacteria biomass can affect the acid-base environment in the water column, migration between water and sediment phases, and transformation processes of DC involving the microbial degradation and mineralization during cyanobacteria decomposition.

\subsection{Influence of sediment on the release of DC in overlying water}

Comparisons of DC release concentrations between presence and absence of sediment during the incubation time are shown in Fig. $5 \mathrm{~b}, 5 \mathrm{~d}, 5 \mathrm{f}$ and $5 \mathrm{~h}$. In the first 16 days, TDC, DOC, and DIC contents with sediments (group SM) were much closer to the treatments without sediments (group M). After that time, however, along with the disappearance of cyanobacteria at the top of overlying water, the releasing intensity of organic carbon became weak. In overlying water, higher values of TDC, DOC, and DOC/TDC ratios in group M but higher DIC values in group SM illustrated a 
faster DOC degradation rate in group SM. Meanwhile, the thickness of the sedimentary detritus

layer in group $\mathrm{M}$ was much higher than in group SM. This indicated a faster decomposition of

detritus in group SM. These discrepancies were probably related to the addition of sediments. In

our microcosm, the abiotic (photochemical) mineralization made a limited contribution to DOC

transformation into DIC because of the protection from light for the entire sides of the plexi-glass

tubes. Instead, the microbial mineralization might play a major role in these processes

(Obernosterer and Benner, 2004). In group SM, the added sediments containing various bacterial

communities elevated the microbial abundance and diversity of community structure (Wang et al.,

2008; Woszczyk, et al., 2011; Shi et al., 2017), compared with group M only added lake water.

Moreover, the added sediments can provide the nutrients to support microbial growth in the water

column (De Vittor et al., 2016). By contrast with group M, the more abundant microorganisms in

quantity and type involved the mineralization from DOC into DIC in group SM added sediment.

Additionally, DOC molecules in overlying water could migrate to the sediments because of the

concentration gradient of DOC at the sediment-water interface. Therefore, the sediments

containing the abundant microbial populations and the high level nutrients probably promoted the

decomposition of cyanobacteria-derived detritus by microorganisms as well as in overlying water

the microbial mineralization from DOC to DIC.

\subsection{Sediment-water interface DC processes during cyanobacteria decomposition}

DC variations at different depths and the diffusive flux of DOC at the sediment-water interface during incubation in treatments with sediment (groups S, SM and SH) are shown in Fig. 
306

307

308

309

310

311

312

313

314

315

316

317

318

319

320

321

322

323

324

325

326

7. The distribution of DC with sediment depth has been shown to illustrate the migration and transformation of organic carbon at the sediment-water interface (Burdige et al., 1999; Vreca, 2003; Chen et al., 2017). In group S, TDC and DIC concentrations had clear differences at sampling depth but no obvious stratification of DOC concentrations. Therefore, the DIC concentration distribution determined the clear stratification of TDC concentrations, when no cyanobacteria biomass decomposed or organic carbons were released in the water-sediment system. The DIC concentration gradient indicated that DIC migrated from pore water to overlying water at the sediment-water interface (Wu et al., 1997; Vreca, 2003). Compared to group S without added cyanobacteria biomass, the DOC concentration gradually decreased with sediment depth after adding cyanobacteria biomass in groups SM and SH (Fig. 7d, 7e and 7f). This was because cyanobacteria decomposition released DOC into the overlying water and increased the DOC concentrations. Contrary to gradients found in previous studies (Alperin et al., 1999; De et al., 2016), these DOC gradients in groups SM and SH revealed that molecules of dissolved organic compounds in overlying water diffused into pore-water at the water-sediment interface. After 43 days of incubation, the groups SM and SH showed that the DOC contents at the bottom water was close to values at depths of $2 \mathrm{~cm}$ and $4 \mathrm{~cm}$ due to the diffusion. The more biomass added, the higher DOC concentrations were detected at each depth, corresponding to the mass balance on carbon budget (Hu et al., 2011; Cremona et al., 2014). Compared with group S, the groups SM and SH had small differences in DOC concentration stratification with sediment depth, while DIC concentrations first increased with depth and then slightly decreased (Fig 7g, 7h and 7i). In addition, most DIC values in groups SM and SH were higher than in group S. The small differences 
327

328

329

and higher DIC values indicated that DOC in overlying water of groups SM and SH diffused to pore water and transformed into DIC. This transformation may have resulted from the microbial mineralization of DOC in sediment (Lojen, 2004; Fahrner et al., 2008; Clayer et al., 2016). After 40 days, in the treatment added the medium biomass (SM) and after 55 days in the treatment added the high biomass (SH), the DOC contents were lower and DIC contents were slightly falling at each depth, compared with the early incubation period. These changes and the associated D-values (Fig. 6d) indicated that gaseous carbons might be generated in the water-sediment system and then released into air, corresponding to in-situ measurements and the carbon model of previous studies (Kuntz et al., 2015; Liu et al., 2017; Yu et al., 2016). Additionally, a certain amount of DIC in groups SM and SH probably migrated to the overlying water at the water-sediment interface, which prompted the increase of DIC concentrations in overlying water (Fig 5e).

The values of DOC flux in groups SM and SH firstly increased and then decreased with incubation time, while group S presented the less DOC flux and little change (Fig. 7j). In general, the diffusive fluxes of DOC at the water-sediment interface increased with the cyanobacteria biomass added in the same time period and displayed a broader range in group SH than groups $\mathrm{S}$ and SM (Fig. 8), corresponding to the vertical variation and the statistical distribution of DOC concentration during cyanobacteria decomposition (Fig. 6b, Fig. 7d, Fig. 7e and Fig. 7f). The diffusive fluxes of DOC reached the maximum value of $411.01 \mathrm{mg} /\left(\mathrm{m}^{2} \cdot \mathrm{d}\right)$ in the treatment added the high cyanobacteria biomass (group $\mathrm{SH}$ ), which was much higher than in the normal water column (Chen et al., 2017). Moreover, the diffusive flux of DOC at the water-sediment interface was negative, indicating that diffusion of DOC from overlying water toward sediment was 
348 occurring. In the latter 16 days, the diffusive flux of DOC gradually declined along the decrease

349 of DOC concentrations in groups SM and SH. Therefore, the decomposition of cyanobacteria in

350 lakes can affect the migration process and the diffusive flux of DOC at the sediment-water 351 interface.

352

\subsection{Implications for the effects of cyanobacteria decomposition on carbon cycling in lakes}

To clarify the feedback of cyanobacteria-derived particulate organic carbon associated with the migration and transformation of DC during accumulated cyanobacteria decomposition in shallow eutrophic lakes, a conceptual diagram is presented according to the DC study of this microcosm system and the previous studies involving the developed model of carbon cycling (Hu et al., 2011), bacterial community dynamics (Shao et al., 2013; Shi et al., 2017) and the releasing mechanism of gaseous carbon (Yu et al., 2016; Yan et al., 2017) during cyanobacterial decomposition (Fig. 9). In eutrophic lakes, the summer monsoon drives a large amount of cyanobacteria blooms to drift near lakeshore. A certain biomass of cyanobacteria gradually accumulate in lakeshore and difficultly spread due to the obstruction of macrophyte-belts or less influence of stormy waves in grooves, thus forming abundant scum with POC. The microcosm results and previous studies indicated that the decline and decomposition of these cyanobacteria scum will change the physicochemical environment (DO, $\mathrm{pH}$, and Eh) and the microbial environment (bacterial community) of lake water (Yan et al., 2017; Shi et al., 2017). Meanwhile, the releasing DOC during cyanobacterial decomposition along with the migration and transformation of DC in water-sediment systems, alter the carbon balance at the water-sediment 
368

369

370

371

372

373

374

375

376

377

378

379

380

381

382

interface and carbon budget of overlying water and pore water in lake ecosystems. These variations

for physicochemical and biophysical environment as well as DOC concentration have a profound effect on carbon cycling in lakes. Therefore, the dynamic state of DC during accumulated cyanobacteria decomposition is an important ecological indicator of biogeochemical processes involving the carbon cycling in shallow eutrophic lakes. These biogeochemical processes mainly include the decomposition of cyanobacteria-derived POC into DOC, transformation of cyanobacteria-derived POC into gaseous carbon, the settlement and burial of cyanobacteriaderived POC into sediment, DOC diffusion at the water-sediment interface, the mineralization and methanogenesis of DOC into DIC, $\mathrm{CO}_{2}$ and $\mathrm{CH}_{4}$, the decomposition of sediments organic matter into DOC.

Moreover, based on visual assessments in the field, the accumulated biomasses of cyanobacteria present the spatial heterogeneity in lake ecosystems due to the differences of lakeshore topographies, lacustrine currents, meteorological factors and ecological types in accumulation areas of cyanobacteria blooms. For example, cyanobacteria blooms in eutrophic lakes are not easy to gather near estuaries but tend to be trapped in macrophyte-belts of lakeshore (Liu et al., 2017; Yan et al., 2017; Huang et al., 2018). The release characteristics of DOC in microcosm added diverse algae biomasses implied that the higher accumulated biomass in lakes can release the more abundant DOC into water column, having the greater potential to change the carbon budget and balance between overlying water and pore water. Meanwhile, the decomposition of diverse cyanobacteria biomasses can cause the differences of physicochemical and biophysical environment and nutrient release (Table 1) among these accumulated 
389

390

391

392

cyanobacteria areas, which will have various impacts on the migration and transformation of DC in spatial scale of eutrophic lakes. Therefore, the qualitative and quantitative dynamic of carbon cycling in eutrophic lakes were significantly affected by the cyanobacteria biomass.

\section{Conclusions}

This study showed that the decomposition of cyanobacteria bloom led to the release of DOC into water column and thus changed the carbon cycling in shallow eutrophic lakes. When the variation range of temperature was not large, the biomass of accumulated cyanobacteria as well as the property of lacustrine sediments can influence the decomposition of cyanobacteria-derived POM to DOC, the mineralization of DOC to DIC, and diffusion processes of DOC and DIC at the water-sediment interface in shallow eutrophic lakes. Furthermore, associated with previous studies about the biogeochemical mechanism of gaseous carbon and solid carbon in lake ecosystems, our study indicated that the dynamic state of DC during accumulated cyanobacteria decomposition is an important ecological indicator of biogeochemical processes in the lacustrine carbon cycling, including the decomposition of cyanobacteria-POC into DOC, the transformation of cyanobacteria-POC into gaseous carbon, the settlement and burial of cyanobacteria-POC into sediment, DOC diffusion at the water-sediment interface, the mineralization and methanogenesis of DOC into DIC, $\mathrm{CO}_{2}$ and $\mathrm{CH}_{4}$, the decomposition of sedimentary organic matter into DOC. In the decomposition process of cyanobacteria blooms, more research effort toward detailed analysis of the biogeochemical fate of cyanobacteria-derived organic carbon in aqueous phase, gas phase and solid phase are needed to obtain a better understanding the influence of cyanobacteria bloom 
409 and eutrophication on the carbon cycling of shallow lakes.

410 Acknowledgments We are particularly grateful to Mr. Xianshen Liu and Mr. Shuang Chen for

411 their kind assistance in samples collecting and laboratory analyses.

\section{References}

413 Aarnos H, Ylostalo P, and Vahatalo AV. 2012. Seasonal phototransformation of dissolved organic 414 matter to ammonium, dissolved inorganic carbon, and labile substrates supporting bacterial 415 biomass across the Baltic Sea. Journal of Geophysical Research-Biogeosciences 117. Artn

Alperin MJ, Albert DB, Martens, CS. 1994. Seasonal variations in production and consumption rates of dissolved organic carbon in an organic-rich coastal sediment. Geochim. Cosmochim. AC. 58: 4909-4930.

Alperin MJ, Martens CS, Albert DB, Suayah IB, Benninger LK, Blair NE, Jahnke RA. 1999. Benthic fluxes and porewater concentration profiles of dissolved organic carbon in sediments from the North Carolina continental slope. Geochimica et Cosmochimica Acta, 63: 427-448.

Assuncao AWD, Souza BP, da Cunha-Santino MB, and Bianchini I. 2016. Formation and mineralization kinetics of dissolved humic substances from aquatic macrophytes decomposition. Journal of Soils and Sediments 18:1252-1264. 10.1007/s11368-016-1519-X

Attermeyer K, Hornick T, Kayler ZE, Bahr A, Zwirnmann E, Grossart HP, and Premke K. 2014. Enhanced bacterial decomposition with increasing addition of autochthonous to allochthonous carbon without any effect on bacterial community composition. 
429

430

431

432

433

434

435

436

437

438

439

440

441

442

443

444

445

446

447

448

449

Biogeosciences 11:1479-1489. 10.5194/bg-11-1479-2014

Bass AM, Waldron S, Preston T, Adams CE, and Drummond J. 2010. Temporal and spatial heterogeneity in lacustrine delta C-13(DIC) and delta O-18(DO) signatures in a large midlatitude temperate lake. Journal of Limnology 69:341-349. 10.3274/J110-69-2-15

Bertilsson, S., Jeremy B., Jones J. 2003. 1-supply of dissolved organic matter to aquatic ecosystems: autochthonous sources. Aquatic Ecosystems, 3-24.

Bo, N., Zweifel, V. L., Jr, C. S. H., Fry, B. 1995. Production and utilization of dissolved organic carbon during an experimental diatom bloom. Limnology \& Oceanography, 40: 898-907.

Brocke HJ, Wenzhoefer F, de Beer D, Mueller B, van Duyl FC, and Nugues MM. 2015. High dissolved organic carbon release by benthic cyanobacterial mats in a Caribbean reef ecosystem. Scientific Reports 5. 10.1038/srep08852

Brown, MR, Jeffrey, SW, Volkman JK, Dunstan GA. 1997. Nutritional properties of microalgae for mariculture. Aquaculture, 151:315-331.

Burdige DJ, Berelson WM, Coale KH, Mcmanus J, Johnson KS. 1999. Fluxes of dissolved organic carbon from California continental margin sediments Geochimica et Cosmochimica Acta, $63: 1507-1515$.

Catalán N, Obrador B, Felip M, and Pretus JL. 2013. Higher reactivity of allochthonous vs. autochthonous DOC sources in a shallow lake. Aquatic Sciences 75:581-593. $10.1007 / \mathrm{s} 00027-013-0302-\mathrm{y}$

Cermelj B, Bertuzzi A, Faganeli J. 1997. Modelling of pore water nutrient distribution and benthic fluxes in shallow coastal waters (Gulf of Trieste, Northern Adriatic). Water Air \& Soil 
Pollution, 99:435-443.

451

452

453

454

455

456

457

458

459

460

461

462

463

464

465

466

467

468

469

470

Chen M, Li XH, He YH, Song N, Cai HY, Wang CH, Li YT, Chu HY, Krumholz LR, and Jiang HL. 2016. Increasing sulfate concentrations result in higher sulfide production and phosphorous mobilization in a shallow eutrophic freshwater lake. Water Research 96:94-104. 10.1016/j.watres.2016.03.030

Chen ML, Kim SH, Jung HJ, Hyun JH, Choi JH, Lee HJ, Huh IA, and Hur J. 2017. Dynamics of dissolved organic matter in riverine sediments affected by weir impoundments: Production, benthic flux, and environmental implications. Water Research 121:150-161. 10.1016/j.watres.2017.05.022.

Clayer F, Gobeil C, Tessier A. 2016. Rates and pathways of sedimentary organic matter mineralization in two basins of a boreal lake: Emphasis on methanogenesis and methanotrophy. Limnology and Oceanography, 61: S131-S149. 10.1002/lno.10323.

Cremona F, Koiv T, Noges P, Pall P, Room EI, Feldmann T, Viik M, and Noges T. 2014. Dynamic carbon budget of a large shallow lake assessed by a mass balance approach. Hydrobiologia 731:109-123. 10.1007/s10750-013-1686-3.

De Vittor C, Relitti F, Kralj M, Covelli S, and Emili A. 2016. Oxygen, carbon, and nutrient exchanges at the sediment-water interface in the Mar Piccolo of Taranto (Ionian Sea, southern Italy). Environmental Science and Pollution Research 23:12566-12581. 10.1007/s11356-0154999-0.

Duan HT, Ma RH, Loiselle SA, Shen QS, Yin HB, and Zhang YC. 2014. Optical characterization of black water blooms in eutrophic waters. Science of the Total Environment 482:174-183. 
Fahrner S, Radke M, Karger D, and Blodau C. 2008. Organic matter mineralisation in the hypolimnion of an eutrophic Maar lake. Aquatic Sciences 70:225-237. 10.1007/s00027-0088008-2

475

476

477

478

479

480

481

482

483

484

485

Feng ZY, Fan CX, Huang WY, and Ding SM. 2014. Microorganisms and typical organic matter responsible for lacustrine "black bloom". Science of the Total Environment 470:1-8. 10.1016/j.scitotenv.2013.09.022

Gómez-Consarnau L, Lindh MV, Gasol JM, Pinhassi J. 2012. Structuring of bacterioplankton communities by specific dissolved organic carbon compounds. Environmental Microbiology 14: 2361-2378. 10.1111/j.1462-2920.2012.02804.x

Han C, Ding SM, Yao L, Shen QS, Zhu CG, Wang Y, and Xu D. 2015. Dynamics of phosphorusiron-sulfur at the sediment-water interface influenced by algae blooms decomposition. Journal of Hazardous Materials 300:329-337. 10.1016/j.jhazmat.2015.07.009

Hanamachi Y, Hama T, and Yanai T. 2008. Decomposition process of organic matter derived from freshwater phytoplankton. Limnology 9:57-69. 10.1007/s10201-007-0232-2

Holcombe BL, Keil RG, and Devol AH. 2001. Determination of pore-water dissolved organic carbon fluxes from Mexican margin sediments. Limnology and Oceanography 46:298-308. 10.4319/1o.2001.46.2.0298

Hu WP, Jorgensen SE, Zhang FB, Chen YG, Hu ZX, and Yang LY. 2011. A model on the carbon cycling in Lake Taihu, China. Ecological Modelling 222:2973-2991. 10.1016/j.ecolmodel.2011.04.018 
492 Huang, H., Xu, X., Shi, C., Liu, X., Wang, G. 2018. Response of taste and odor compounds to 493 elevated cyanobacteria biomass and temperature. Bulletin of Environmental Contamination \& Toxicology, 101: 1-7. 10.1007/s00128-018-2386-5

495

496

497

498

499

500

501

502

503

504

505

506

507

508

509

510

511

512

Hulatt CJ, Thomas DN, Bowers DG, Norman L, and Zhang C. 2009. Exudation and decomposition of chromophoric dissolved organic matter (CDOM) from some temperate macroalgae. Estuarine Coastal and Shelf Science 84:147-153. 10.1016/j.ecss.2009.06.014

Jaffe R, McKnight D, Maie N, Cory R, McDowell WH, and Campbell JL. 2008. Spatial and temporal variations in DOM composition in ecosystems: The importance of long-term monitoring of optical properties. Journal of Geophysical Research-Biogeosciences 113. 10.1029/2008JG000683

Khodse, V. B., Bhosle, N. B. 2011. Bacterial utilization of size-fractionated dissolved organic matter. Aquatic Microbial Ecology, 64: 299-309. 10.3354/ame01529

Koehler B, Broman E, and Tranvik LJ. 2016. Apparent quantum yield of photochemical dissolved organic carbon mineralization in lakes. Limnology and Oceanography 61:2207-2221. 10.1002/lno.10366

Komada T, Burdige DJ, Crispo SM, Druffel ERM, Griffin S, Johnson L, and Le D. 2013. Dissolved organic carbon dynamics in anaerobic sediments of the Santa Monica Basin. Geochimica Et Cosmochimica Acta 110:253-273. 10.1016/j.gca.2013.02.017

Kong F, Gao G. 2005. Hypothesis on cyanobacteria bloom-forming mechanism in large shallow eutrophic lakes. Acta Ecologica Sinica 25: 589-595.

Kuntz LB, Laakso TA, Schrag DP, and Crowe SA. 2015. Modeling the carbon cycle in Lake 
Lahajnar N, Rixen T, Gaye-Haake B, Schafer P, and Ittekkot V. 2005. Dissolved organic carbon (DOC) fluxes of deep-sea sediments from the Arabian Sea and NE Atlantic. Deep-Sea

Research Part Ii-Topical Studies in Oceanography 52:1947-1964.

Lee Y, Lee B, Hur J, Min JO, Ha SY, Ra K, Kim KT, and Shin KH. 2016. Biodegradability of

Liu X, He R, Shi Y, Yan ZS, Wang CH, and Jiang HL. 2016. Identifying the chemical composition (in Chinese) 31: 2652-2660.

Li K, Guan B, Liu Z. 2011. Experiments on decomposition rate and release forms of nitrogen and phosphorus from the decomposing cyanobacterial detritus. Journal of Lake Science (in Chinese) 23: 919-925.

Liu G, He J, Fan C., Zhang L, Shen Q, Zhong J, Yan S. 2010. Environment effects of algae-caused black spots: impacts on Fe-Mn-S cycles in water-sediment interface. Environment Science. of decomposed residues from cyanobacterial bloom biomass by Pyrolysis-GC/MS. CleanSoil Air Water 44:1636-1643. 10.1002/clen.201500283

Liu XS, Shi CF, Xu XG, Li XJ, Xu Y, Huang HY, Zhao YP, Zhou YW, Shen HC, Chen C, and Wang GX. 2017. Spatial distributions of beta-cyclocitral and beta-ionone in the sediment and overlying water of the west shore of Taihu Lake. Science of the Total Environment 579:430438. 10.1016/j.scitotenv.2016.11.079 
534 Lojen S, Ogrinc N, Dolenec T, Vokal B, Szaran J, Mihelcic G, and Branica M. 2004. Nutrient

535 fluxes and sulfur cycling in the organic-rich sediment of Makirina Bay (Central Dalmatia,

536 Croatia). Science of the Total Environment 327:265-284. 10.1016/j.sciotenv.2004.01.011

537 Marie L, Pernet-Coudrier B, Waeles M, Gabon M, and Riso R. 2015. Dynamics and sources of

538 reduced sulfur, humic substances and dissolved organic carbon in a temperate river system

539 affected by agricultural practices. Science of the Total Environment 537:23-32.

$540 \quad$ 10.1016/j.scitotenv.2015.07.089

541 McDonald CP, Stets EG, Striegl RG, and Butman D. 2013. Inorganic carbon loading as a primary

542 driver of dissolved carbon dioxide concentrations in the lakes and reservoirs of the contiguous

543 United States. Global Biogeochemical Cycles 27:285-295. 10.1002/gbc.20032

544 Obernosterer I, and Benner R. 2004. Competition between biological and photochemical processes

545 in the mineralization of dissolved organic carbon. Limnology and Oceanography 49:117-124.

546 Quay PD, Emerson SR, Quay BM, Devol AH. 1986. The carbon cycle for Lake Washington-a

$547 \quad$ stable isotope study. Limnology and Oceanography 31: 596-611.

548 Seeberg-Elverfeldt J, Schluter M, Feseker T, and Kolling M. 2005. Rhizon sampling of porewaters

549 near the sediment-water interface of aquatic systems. Limnology and Oceanography-Methods

$550 \quad 3: 361-371.10 .4319 /$ lom.2005.3.361

551 Shao KQ, Gao G, Chi KX, Qin BQ, Tang XM, Yao X, and Dai JY. 2013. Decomposition of

552 Microcystis blooms: Implications for the structure of the sediment bacterial community, as

553 assessed by a mesocosm experiment in Lake Taihu, China. Journal of Basic Microbiology

$554 \quad 53: 549-554.10 .1002 /$ jobm. 201100532 
555 Shi LM, Huang YX, Zhang M, Yu Y, Lu YP, and Kong FX. 2017. Bacterial community dynamics

556

557

558

559

560

561

562

563

564

565

566

567

568

569

570

571

572

573

574

575

and functional variation during the long-term decomposition of cyanobacterial blooms invitro. Science of the Total Environment 598:77-86. 10.1016/j.scitotenv.2017.04.115

Shoaf WT, Lium BW. 1976. Improved extraction of chlorophyll a and b from algae using dimethyl sulfoxide. Limnology and Oceanography 21: 926-928.

Shotbolt L. 2010. Pore water sampling from lake and estuary sediments using Rhizon samplers. Journal of Paleolimnology 44:695-700. 10.1007/s10933-008-9301-8

Smith JL, Boyer GL, Zimba PV. 2008. A review of cyanobacterial odorous and bioactive metabolites: Impacts and management alternatives in aquaculture. Aquaculture 280: 5-20. 10.1016/j.aquaculture.2008.05.007

Song N, He YH, and Jiang HL. 2016. Inferior adaptation of bay sediments in a eutrophic shallow lake to winter season for organic matter decomposition. Environmental Pollution 219:794-803. 10.1016/j.envpol.2016.07.057

Sobek S, Soderback B, Karlsson S, Andersson E, and Brunberg AK. 2006. A carbon budget of a small humic lake: An example of the importance of lakes for organic matter cycling in boreal catchments. Ambio 35:469-475. 10.1579/0044-7447(2006)35[469:Acboas]2.0.Co;2

Steinberg C. 2003. Ecology of humic substances in freshwaters: determinants from geochemistry to ecological niches. Springer, Berlin.

Sun Y. 2013. Study on the aerobic decomposition and nutrient release of cyanobacteria detritus in Dianshan Lake. China Environ. Sci. (in Chinese) 33: 2047-2052.

Tibbetts SM, Milley JE, and Lall SP. 2015. Chemical composition and nutritional properties of 
freshwater and marine microalgal biomass cultured in photobioreactors. Journal of Applied

Phycology 27:1109-1119. 10.1007/s10811-014-0428-x

Tranvik LJ. 1992. Allochthonous dissolved organic matter as an energy source for pelagic bacteria and the concept of the microbial loop. Hydrobiologia 229: 07-114.

Vreca P. 2003. Carbon cycling at the sediment-water interface in a eutrophic mountain lake (Jezero

Wang Y, Chen F. 2008. Decomposition and phosphorus release from four different size fractions of Microcystis spp. taken from Lake Taihu, China. Journal of Environmental Sciences 20:891-896.

Woszczyk M, Bechtel A, and Cieslinski R. 2011. Interactions between microbial degradation of sedimentary organic matter and lake hydrodynamics in shallow water bodies: insights from Lake Sarbsko (northern Poland). Journal of Limnology 70:293-304. 10.3274/J111-70-2-09

Wu F, Qing H, Wan G, Tang D, Huang R, Cal Y. 1997. Geochemistry of $\mathrm{HCO}_{3}{ }^{-}$, at the sedimentwater interface of lakes from the Southwestern Chinese Plateau. Water, Air, \& Soil Pollution 99: 381-389.

Yan XC, Xu XG, Wang MY, Wang GX, Wu SJ, Li ZC, Sun H, Shi A, and Yang YH. 2017. Climate warming and cyanobacteria blooms: Looks at their relationships from a new perspective. 
Yang LY, Chen CTA, Lui HK, Zhuang WE, and Wang BJ. 2016. Effects of microbial transformation on dissolved organic matter in the east Taiwan Strait and implications for carbon and nutrient cycling. Estuarine Coastal and Shelf Science 180:59-68. 10.1016/j.ecss.2016.06.021

602

603

604

605

606

607

608

609

610

611

612
Yang Z, Zhang M, Shi XL, Kong FX, Ma RH, and Yu Y. 2016. Nutrient reduction magnifies the impact of extreme weather on cyanobacterial bloom formation in large shallow Lake Taihu (China). Water Research 103:302-310. 10.1016/j.watres.2016.07.047

Ye LL, Shi X, Wu XD, Zhang M, Yu Y, Li DM, Kong FX. 2011. Dynamics of dissolved organic carbon after a cyanobacterial bloom in hypereutrophic Lake Taihu (China). Limnologica, 41: 382-388. 10.1016/j.limno.2011.06.001

Yu DZ, Xie P, Zeng C, Xie LJ, Chen J. 2016. In situ enclosure experiments on the occurrence, development and decline of black bloom and the dynamics of its associated taste and odor compounds. Ecological Engineering 87: 246-253. 10.1016/j.ecoleng.2015.11.039

Zarel T, Sinetova MA, Cerveny, J. 2015. Measurement of chlorophyll a and carotenoids concentration in cyanobacteria. Bio-protocol 5: 1-5. 


\section{Table $\mathbf{1}$ (on next page)}

Physical and chemical properties and the concentrations of $\mathrm{TN}, \mathrm{TP}, \mathrm{NH}_{4}{ }^{+}-\mathrm{N}, \mathrm{NO}_{3}{ }^{-} \mathrm{N}$ and $\mathrm{DOC}$ in the lake water from accumulated cyanobacteria areas of lakeshore and open water of Taihu Lake. 


\begin{tabular}{|c|c|c|c|c|c|c|c|c|c|c|c|}
\hline Lake region & $\begin{array}{l}\text { Cyanobacterial } \\
\text { thickness }(\mathrm{cm})\end{array}$ & $\begin{array}{l}\text { Depth of } \\
\text { water (m) }\end{array}$ & $\begin{array}{l}\text { Temperatur } \\
\text { e } \\
\left({ }^{\circ} \mathrm{C}\right)\end{array}$ & $\mathrm{pH}$ & $\begin{array}{l}\text { DO } \\
(\mathrm{mg} / \mathrm{L})\end{array}$ & $\begin{array}{l}\text { Eh } \\
(\mathrm{mv})\end{array}$ & $\begin{array}{l}\mathrm{TN} \\
(\mathrm{mg} / \mathrm{L})\end{array}$ & $\begin{array}{l}\mathrm{TP} \\
(\mathrm{mg} / \mathrm{L})\end{array}$ & $\begin{array}{l}\mathrm{NH}_{4}{ }^{+}-\mathrm{N} \\
(\mathrm{mg} / \mathrm{L})\end{array}$ & $\begin{array}{l}\mathrm{NO}_{3}^{-}-\mathrm{N} \\
(\mathrm{mg} / \mathrm{L})\end{array}$ & $\mathrm{DOC}(\mathrm{mg} / \mathrm{L})$ \\
\hline $\begin{array}{l}\text { Accumulated } \\
\text { cyanobacteria } \\
\text { areas of lakeshore }\end{array}$ & $4.0-10.0$ & $0.3-0.6$ & $27.6-28.4$ & $6.7-7.4$ & $0.5-1.5$ & -222.9 to -64.1 & $4.45-8.89$ & $0.49-1.89$ & $0.70-5.97$ & $0.01-0.56$ & $23.08-103.60$ \\
\hline Open water & $0-0.2$ & $0.7-3.1$ & $27.8-28.6$ & $6.9-9.3$ & $\begin{array}{l}6.1- \\
16.4\end{array}$ & $86.7-219.3$ & $1.59-4.51$ & $0.24-0.44$ & $0.05-0.17$ & $0.63-1.64$ & $15.09-21.34$ \\
\hline
\end{tabular}


Table 2 (on next page)

Pearson correlation coefficients between DCs concentrations and physicochemicalindexes in different treatments $(p<0.05)$. 


\begin{tabular}{lllllll}
\hline \multirow{2}{*}{ Treatments } & DOC & \multicolumn{5}{l}{ DIC } \\
\cline { 2 - 7 } & DOC-DO & DOC-Eh & DOC-pH & DIC-DO & DIC-Eh & DIC-pH \\
\hline S & 0.127 & -0.017 & 0.300 & 0.024 & 0.015 & 0.291 \\
SM & $\mathbf{- 0 . 3 2 3}$ & $\mathbf{- 0 . 4 0 7}$ & $\mathbf{- 0 . 4 7 1}$ & -0.152 & -0.094 & $\mathbf{0 . 8 1 7}$ \\
SH & $\mathbf{- 0 . 3 1 0}$ & -0.214 & $\mathbf{- 0 . 5 3 3}$ & -0.191 & -0.423 & $\mathbf{0 . 5 8 1}$ \\
M & $\mathbf{- 0 . 3 2 8}$ & -0.285 & -0.202 & -0.197 & 0.015 & $\mathbf{0 . 7 6 8}$ \\
\hline
\end{tabular}

1 
Figure 1

Location of the sampling sites, Google Maps of trenches, and accumulated cyanobacteria in aquatic macrophyte-belts in the western shoreline of Taihu Lake, China.

Location of the sampling sites (a), Google Maps of trenches (b), and macrophyte-belts (c). Map credit: @ 2016 Google; Digital Globe.

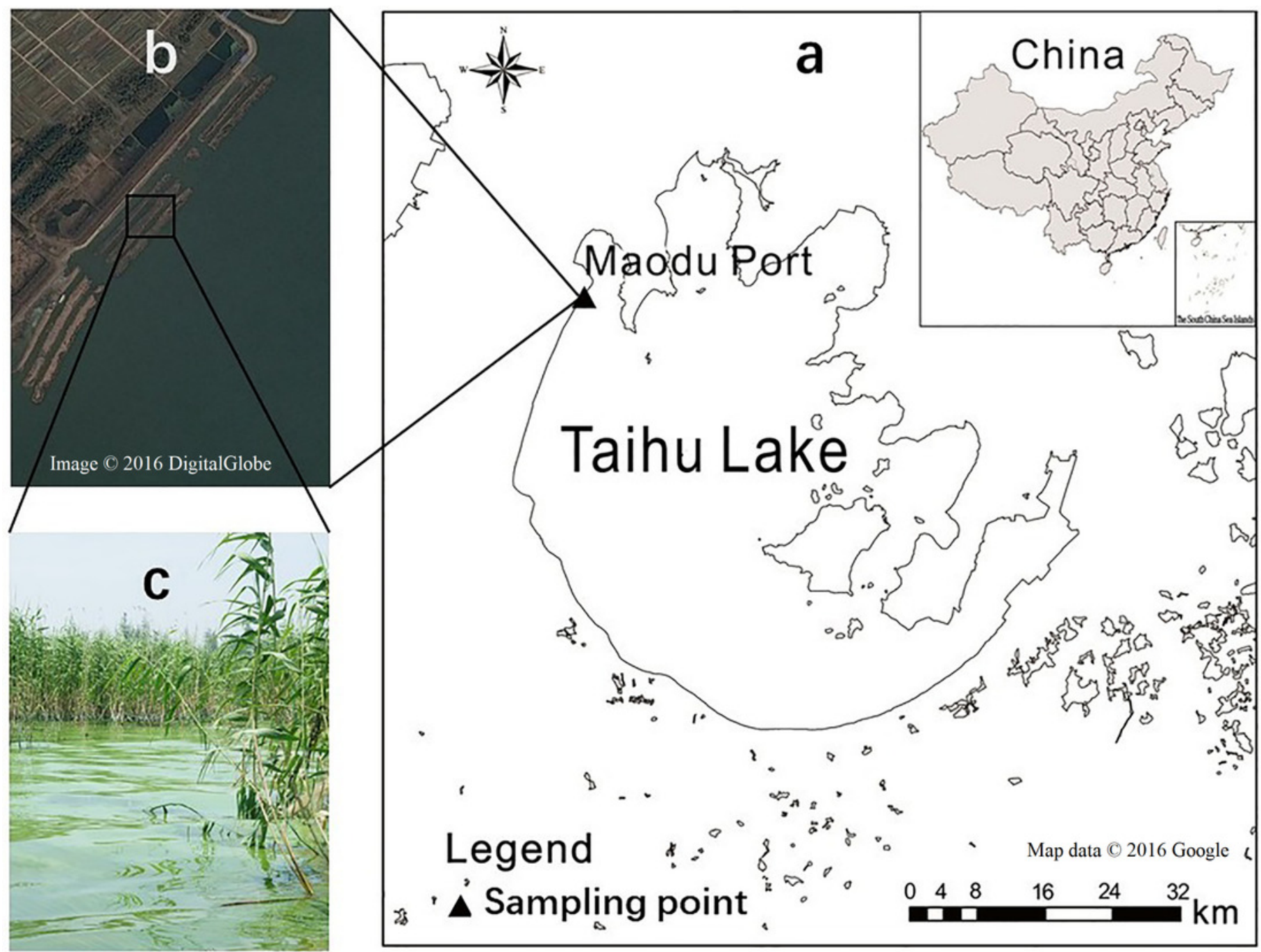


Figure 2

Microcosm system in in the laboratory for simulating the decomposition of accumulated cyanobacteria in lakeshore of Taihu Lake.

$0 \mathrm{~g}, 235 \mathrm{~g}$ and $470 \mathrm{~g}$ cyanobacteria biomass were added into three water columns with sediment named as S, SM and $\mathrm{SH}$, respectively, while $235 \mathrm{~g}$ cyanobacteria biomass was added in the control system without sediment, named $\mathrm{M}$. In the system, $235 \mathrm{~g}$ and $470 \mathrm{~g}$ cyanobacteria biomass can cause $5 \mathrm{~cm}$ and $10 \mathrm{~cm}$ cyanobacteria accumulation layer, respectively.

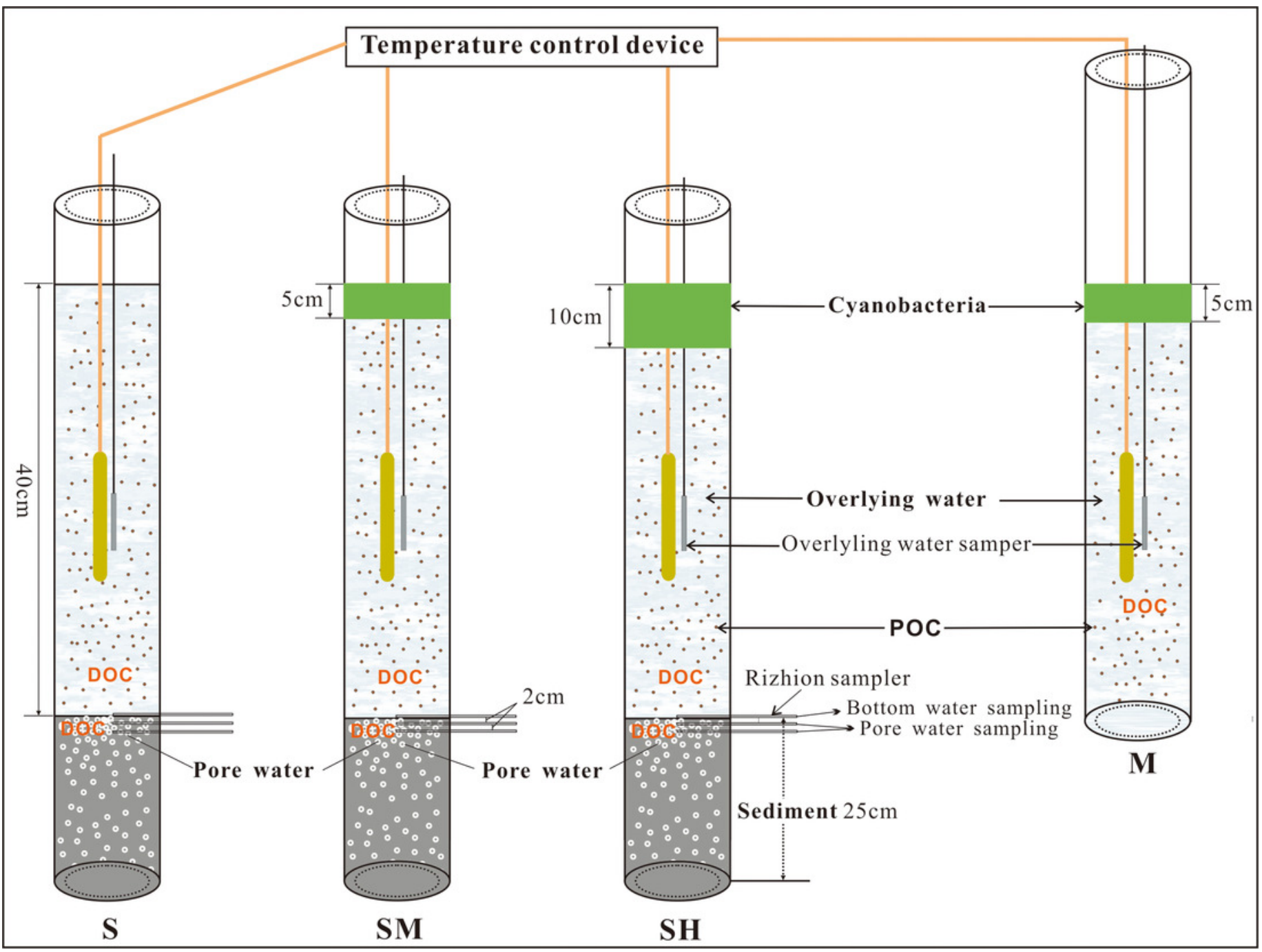


Figure 3

Variations of cyanobacteria thicknesses of superficial overlying water and the thicknesses of sedimentary detritus layer from cyanobacteria particulates at the bottom of overlying water.

Cyanobacteria thicknesses of superficial overlying water (a). The thicknesses of sedimentary detritus layer from cyanobacteria particulates at the bottom of overlying water (b).
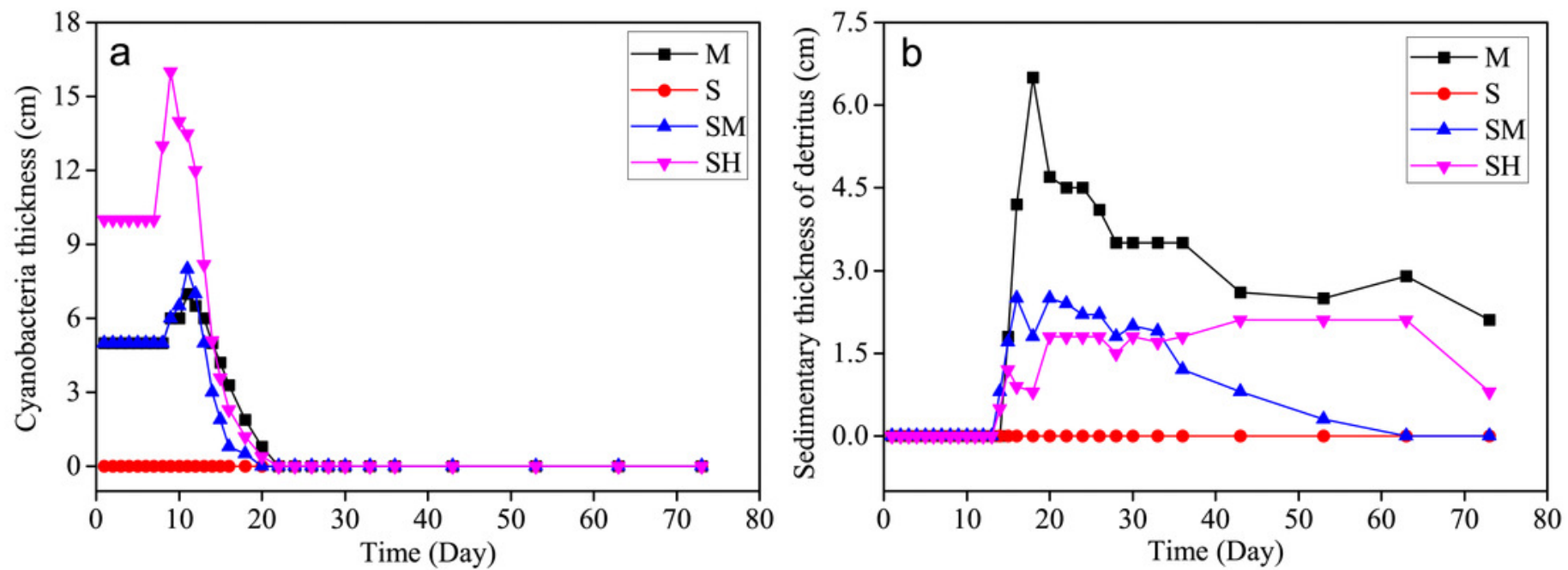
Figure 4

Variations of $\mathrm{DO}$, Eh and $\mathrm{pH}$ along with the incubation time in each treatment.

$\mathrm{DO}(\mathrm{a})$, Eh (b) and pH (c).
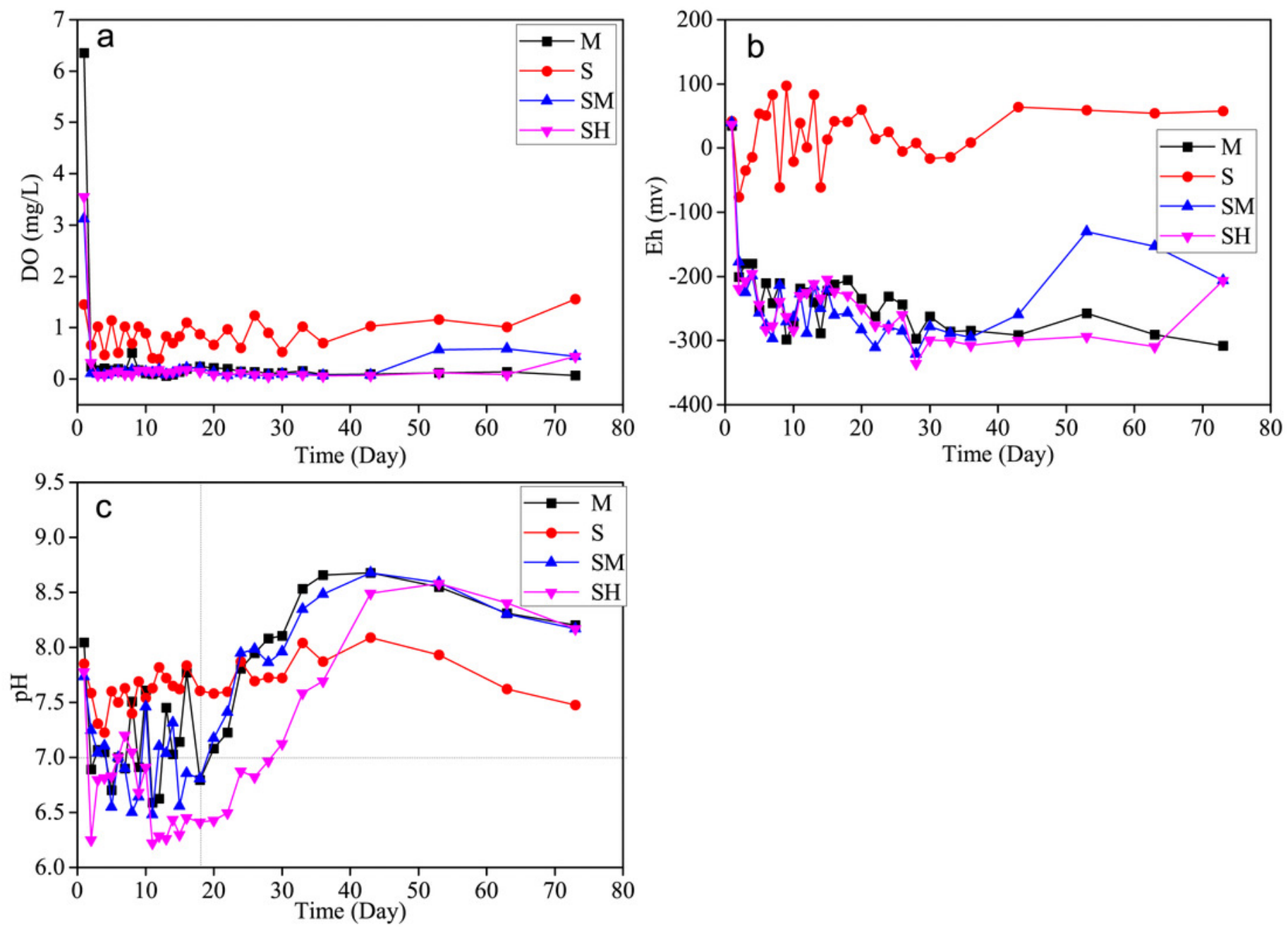
Figure 5

Variations of TDC, DOC, DIC and DOC/TDC ratios during incubation in overlying water of each treatment including the influence of cyanobacteria biomass and absence or presence of sediments.

$\operatorname{TDC}(a, b), \operatorname{DOC}(c, d), \operatorname{DIC}(e, f)$ and DOC/TDC ratios $(g, h)$. The influence of added cyanobacteria biomass $(a, c, e, g)$. The influence for absence or presence of sediments (b, $d$, $f, h)$.
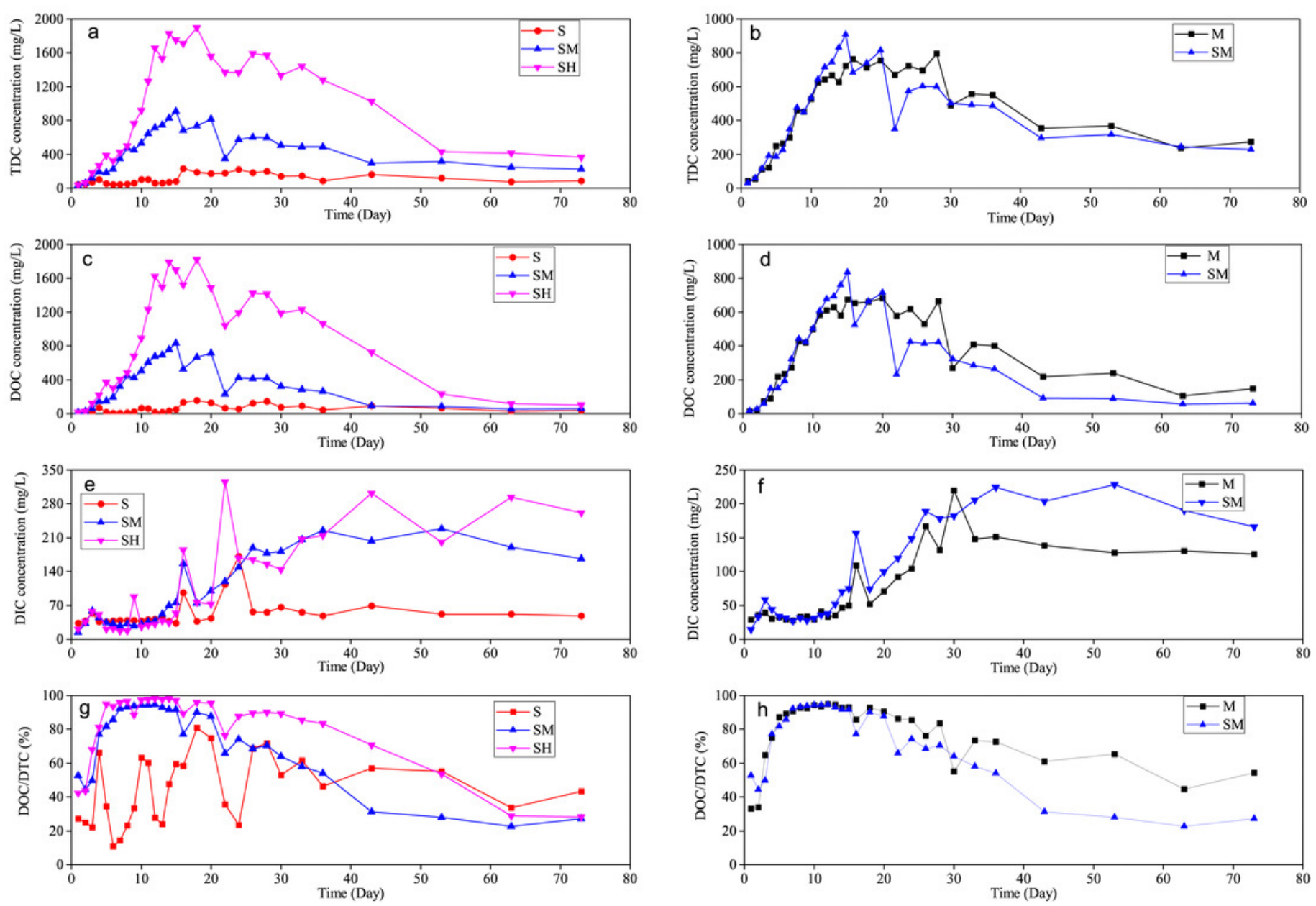
Figure 6

Statistical box-plots of TDC, DOC and DIC and comparison of D-values in treatments added different cyanobacterial biomasses.

TDC (a), DOC (b) and DIC (c) and comparison of D-values (d). D-value means the max TDC concentration in incubation subtracts the sum of DOC and DIC values in final stage in each treatment.
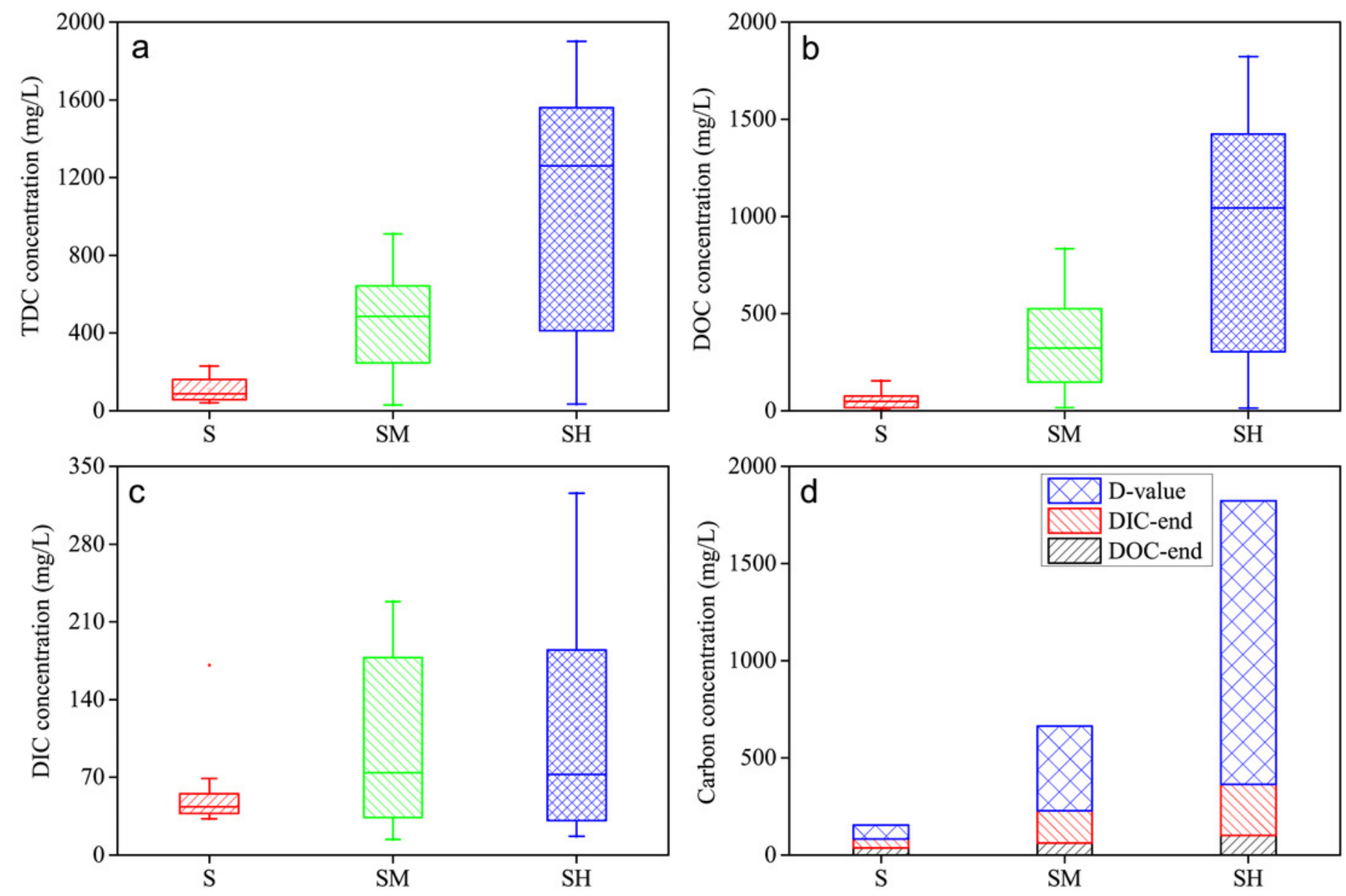
Figure 7

Variations of TDC, DIC, DOC and diffusive fluxes of DOC at the sediment-water interface with incubation time in each treatment added different cyanobacteria biomass.

TDC ( $a, b$ and $c)$, DIC (e, f and $g), D O C$ ( $g, h$ and $i)$ and diffusive fluxes of DOC (j). 

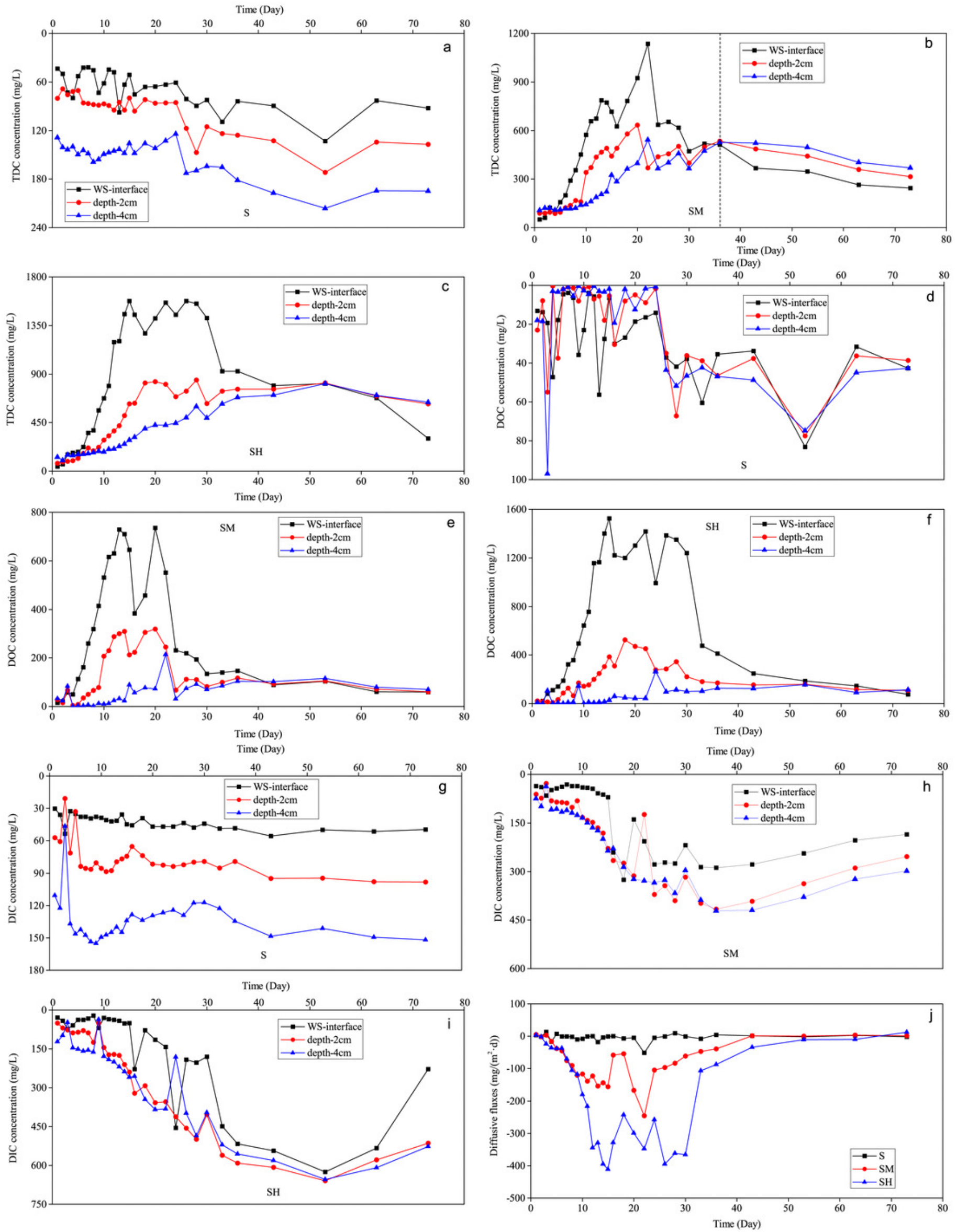
Figure 8

Statistical box-plot of the diffusive fluxes of DOC at the sediment-water interface in each experimental group.

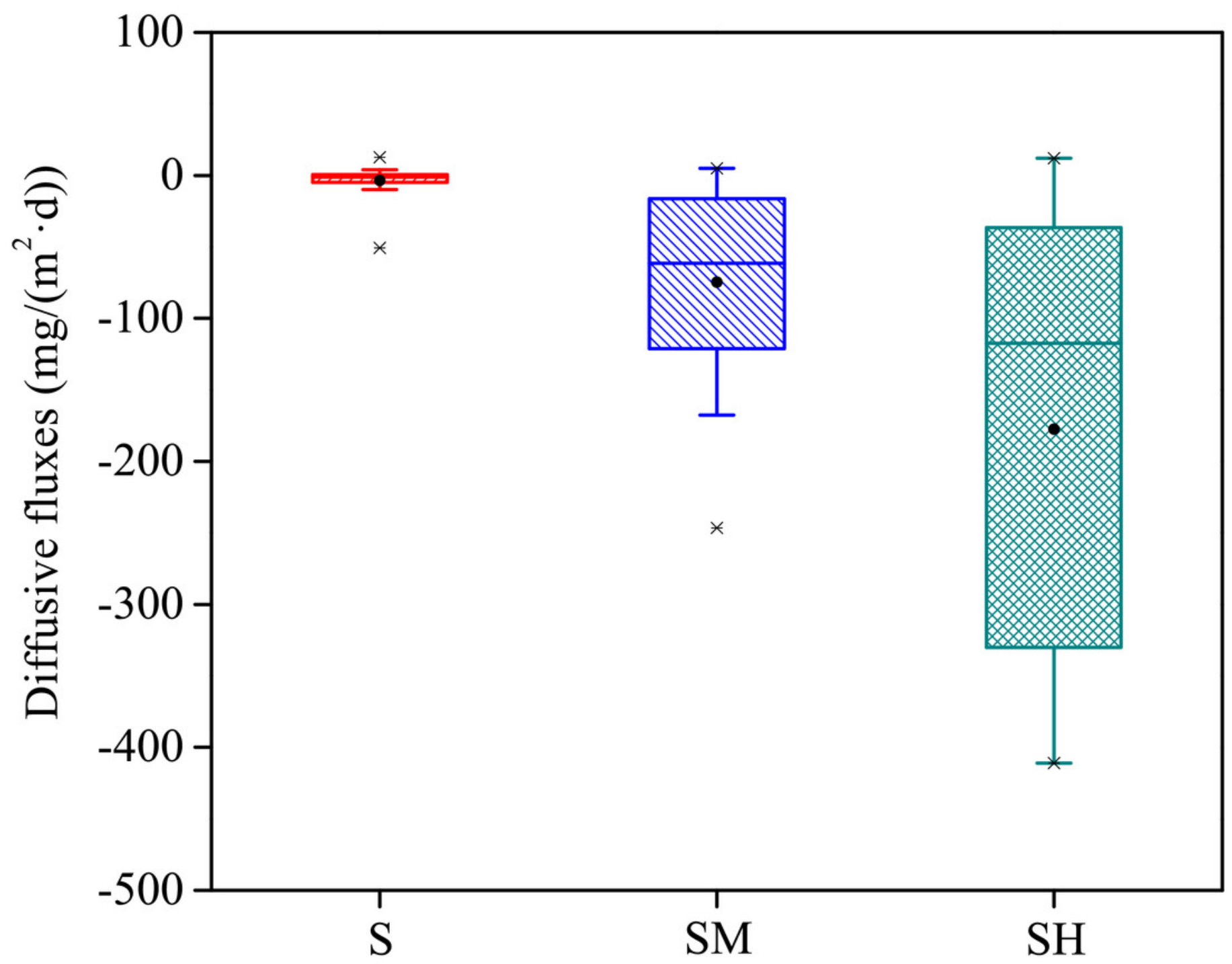




\section{Figure 9}

Migration and transformation of DC generated by accumulated cyanobacteria in aquatic plant-belts and trenches of Taihu Lake, China.

Solid arrow and dotted arrow represent the implications of this study and the previous studies, respectively. Cyanobacteria-derived POC was biologically degraded into DOC, and may result in the decrease of $\mathrm{pH}$ values and anoxic state in lake water (a). A little Cyanobacteria-derived POC decomposed into DOC (b). Cyanobacteria-derived POC were transformed into gaseous carbon (Smith et al., 2008; Liu et al., 2017; Huang et al., 2018) (c). Cyanobacteria-derived POC deposited into organic matter at the top of sediment and contribute to humification and carbon burial (Hu et al., 2011; Kuntz et al., 2015; Marie et al., 2015) (d). DOC diffused from overlying water to pore water (e). A little DOC volatilized into Atmosphere (Yu et al., 2016; Liu et al., 2017; Huang et al., 2018) (f). DOC mineralization (g). Organic matter decomposition (h). Organic matter mineralization (i). Organic matter methanogenesis produced $\mathrm{CO}_{2}$ and $\mathrm{CH}_{4}$ (Clayer et al., 2016; Yan et al., 2017) (j). DIC diffusion at the water-sediment interface causing the increase of $\mathrm{pH}$ value (k). $\mathrm{CO}_{2}$ diffusion at the water-air interface (Yan et al., 2017) (I). Some DOC may be also assimilated by bacteria thus transformed to POC (Bo et al., 1995; Khodse et al., 2011; Yang et al., 2016) (m).

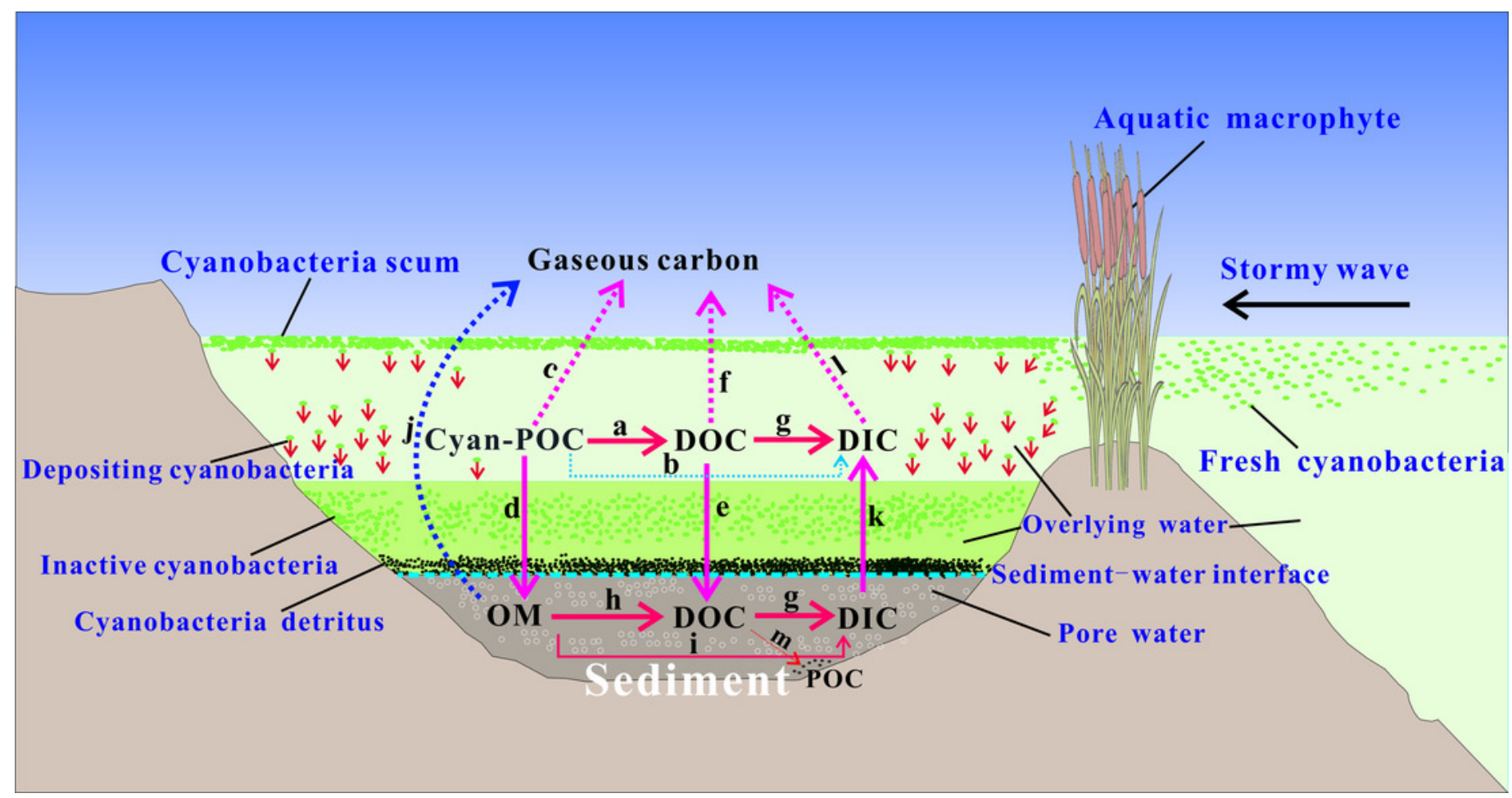

